Bài báo khoa hoc

\title{
Đánh giá diễn biến chất lượng nước sông Đáy đoạn chảy qua tỉnh Nam Định giai đoạn 2011-2019
}

\section{Đỗ Hữu Tuấn ${ }^{1 *}$, Lê Thúy Diệu ${ }^{1}$}

${ }^{1}$ Khoa môi trường, Trường Đại học Khoa học Tự nhiên, Đại học Quốc gia Hà Nội. Địa chỉ: 334 Nguyễn Trãi, Thanh Xuân Hà Nội; tuandh@vnu.edu.vn; dieuthuy.mt45@gmail.com

*Tác giả liên hệ: tuandh@vnu.edu.vn; Tel.: +84-2438584995

Ban Biên tập nhận bài: 22/10/2021; Ngày phản biện xong: 5/12/2021; Ngày đăng bài: $25 / 2 / 2022$

Tóm tắt: Diễn biến chất lượng nước sông là một trong những nội dung quan trọng trong công tác quản lý môi trường nói chung và công tác quản lý môi trường nước nói riêng. Kết quả đánh giá làm căn cứ cho các quyết định về quản lý nhà nước về công tác bảo vệ môi trường. Các phương pháp đánh giá chất lượng nước theo chỉ số riêng lẻ, chỉ số tổng hợp và phân tích xu thế đã được sử dụng trong ghiên cứu này để đánh giá diê̂n biến chất lượng nước sông Đáy đoạn chảy qua tỉnh Nam Định trong giai đoạn 2011-2019. Kết quả phân tích xu thế các chỉ tiêu chất lượng nước cho thấy các thông số $\mathrm{COD}, \mathrm{BOD}_{5}$, Nitrat, Coliform có xu thế giảm từ 2011-2019, thông số $\mathrm{NH}_{4}^{+}$có xu thế tăng nhẹ, các thông số $\mathrm{TSS}, \mathrm{PO}_{4}{ }^{3-}, \mathrm{Cr}^{6+}$ có xu thế ổn định. Nghiên cứu cho thấy chất lượng nước sông Đáy đoạn chảy qua tỉnh Nam Định có chất lượng tốt và ngày càng được cải thiện từ 2011-2019. Các giá trị trung bình quan trắc từ 2011-2019 đều nằm dưới QCVN 08-MT:2015/BTNMT cột B1.

Từ khóa: Chất lượng nước; Diễn biến chất lượng nước; Sông Đáy; WQI.

\section{Mở đầu}

Đánh giá chất lượng nước là một trong những nội dung quan trọng của công tác quản lý các lưu vực sông. Trong đánh giá chất lượng nước hiện nay có đánh giá hiện trạng, đánh giá tác động, đánh giá diễn biến và dự báo xu thế biến đổi của chất lượng nước trong tương lai. Việc quan trắc và đánh giá chất lượng nước định kỳ có ý nghĩa rất quan trọng trong việc ra các quyết định của các nhà quản lý môi trường và phục vụ cho công tác phát triển kinh tế xã hội. Đánh giá chất lượng nước sông là công việc rất quan trọng phục vụ nhiều mục đích khác nhau như để đánh giá hiện trạng nước sông [1], đánh giá diễ̉n biến chất lượng nước [2], đánh giá rủi ro ô nhiễm tới sức khỏe con người [3-4], rủi ro môi trường [5], hoặc theo dõi và đánh giá các chất ô nhiễm tiềm tàng [6] cũng như đưa ra các dự báo xu thế biến động chất lượng nước [7-9].

Các phương pháp sử dụng để đánh giá chất lượng nước sông cũng rất đa dạng từ việc đánh giá bằng các chỉ số riêng lẻ [10], các chỉ số tổng hơp chất lượng nước [11-14], bằng các phương pháp thống kê [15-19], phương pháp mô hình hóa [20-21], trí tuệ nhân tạo [2223]. Các phương pháp tuy có khác nhau về cách thức tính toán nhưng đều có mục tiêu là đánh giá được hiện trạng chất lượng nước làm căn cứ cho các quyết định của các nhà quản lý. Các nghiên cứu sử dụng giá trị quan trắc của các thông số chất lượng nước, xử lý thống kê, tính toán các chỉ số thành phần từ đó đưa rác các đánh giá về chất lượng, diễn biến và xu thế. Do 
đó phương pháp phân tích thống kê và chỉ số chất lượng nước tổng hợp được lựa chọn để nghiên cứu chất lượng nước sông Đáy là phù hợp.

Lưu vực sông Đáy có ý nghĩa rất quan trọng trong phát triển kinh tế xã hội của khu vực đồng bằng Sông Hồng. Các nghiên cứu gần đây chỉ ra rằng chất lượng nước sông Đáy đang bị ảnh hưởng do các hoạt động phát triển kinh tê xã hội trong lưu vực [24-25]. Sông Đáy đoạn chảy qua tỉnh Nam Định có vai trò to lớn trong việc cung cấp nước phục vụ phát triển kinh tế xã hội của hai tỉnh Nam Định và Ninh Bình trước khi chảy ra biển. Trong đó vai trò cung cấp nguồn nước phục vụ cho phát triển nông nghiệp là rất quan trọng. Việc quan trắc và đánh giá chất lượng nước sông Đáy và diễn biến của nó nhằm đưa ra các căn cứ phục vụ cho các kế hoạch phát triển kinh tế xã hội của khu vực cũng như bảo vệ và nâng cao chất lượng nước sông là rất có ý nghĩa khoa học và thực tiê̂́n.

Trong nghiên cứu này, phương pháp phân tích thống kê kết hợp chỉ số chất lượng nước để đánh giá diễn biến chất lượng nước sông khu vực nghiên cứu với các mục tiêu bao gồm: (1) Đánh giá được diễn biến chất lượng nước sông Đáy đoạn chảy qua tỉnh Nam Định; (2) Xác định được xu thế biến đổi của chất lượng nước từ năm 2011 đến 2019 . Kết quả nghiên cứu là căn cứ quan trọng giúp các nhà quản lý môi trường có những quyết định đúng trong công tác bảo vệ môi trường của địa phương, đặc biệt là môi trường nước sông Đáy.

\section{Phương pháp nghiên cứu}

\section{1. Đối tượng và phạm vi nghiên cưu}

Đối tượng nghiên cứu là chất lượng nước sông Đáy đoạn chảy qua tỉnh Nam Định với các thông số: $\mathrm{pH}, \mathrm{COD}, \mathrm{BOD}_{5}, \mathrm{DO}, \mathrm{SS}, \mathrm{Amoni} \mathrm{NO}_{3}{ }^{-}, \mathrm{NO}_{2}{ }^{-}, \mathrm{PO}_{4}{ }^{3-}, \mathrm{Cr}^{6+}$, Coliform.

Phạm vi nghiên cứu: sông Đáy đoạn chảy qua tỉnh Nam Định (Hình 1).

\subsection{Phưong pháp nghiên cúu}

\subsubsection{Phương pháp thu thập dữ liệu}

Dữ liệu quan trắc được thu thập tại 6 điểm quan trắc dọc sông Đáy từ năm 2011 đến năm 2019 tần suất 4 lần/năm làm cơ sở đánh giá diễn biến chất lượng nước sông (Bảng 1).

Bảng 1. Tọa độ vị trí các điểm quan trắc.

\begin{tabular}{|c|c|c|c|c|c|c|}
\hline \multirow{2}{*}{ TT } & \multirow{2}{*}{\multicolumn{2}{|c|}{ Vị trí quan trắc }} & \multirow{2}{*}{$\begin{array}{l}\text { Kí hiệu } \\
\text { mẫu }\end{array}$} & \multicolumn{2}{|c|}{ Tọa độ } & \multirow{2}{*}{ Ghi chú } \\
\hline & & & & $\mathbf{X}$ & $\mathbf{Y}$ & \\
\hline 1 & $\begin{array}{l}\text { Xã Yên } \\
\text { Phong }\end{array}$ & & M1 & $105^{\circ} 57^{\prime} 16,2^{\prime \prime}$ & $20^{\circ} 19^{\prime} 15,7^{\prime \prime}$ & Khu vực đầu sông \\
\hline 2 & $\begin{array}{l}\text { Xã Yên } \\
\text { Quang }\end{array}$ & Huyện Ý & M2 & $105^{\circ} 59^{\prime} 12,2^{\prime \prime}$ & $20^{\circ} 17^{\prime} 09,1^{\prime \prime}$ & $\begin{array}{l}\text { Khu vực trạm cấp nước } \\
\text { sinh hoạt xã Yên Quang }\end{array}$ \\
\hline 3 & $\begin{array}{l}\text { Xã Yên } \\
\text { Trị }\end{array}$ & Yên & M3 & $106^{\circ} 03^{\prime} 01,4^{\prime \prime}$ & $20^{\circ} 14^{\prime} 44,5^{\prime}$, & $\begin{array}{l}\text { Vị trí sau khi sông Sắt } \\
\text { nhập lưu với sông Đáy } \\
\text { khoảng } 1,5 \mathrm{~km} \text { về phía hạ } \\
\text { lưu. }\end{array}$ \\
\hline 4 & $\begin{array}{l}\text { Xã } \\
\text { Hoàng } \\
\text { Nam }\end{array}$ & & M4 & $106^{\circ} 06^{\prime} 09,6^{\prime \prime}$ & $20^{\circ} 14^{\prime} 16,2^{\prime \prime}$ & $\begin{array}{l}\text { Vị trí cách điểm nhập lưu } \\
\text { với sông Đào khoảng } 1,5 \\
\text { km về phía hạ lưu. }\end{array}$ \\
\hline 5 & $\begin{array}{l}\text { Xã Nghĩa } \\
\text { Sơn }\end{array}$ & $\begin{array}{l}\text { Huyện } \\
\text { Nghĩa } \\
\text { Hưng }\end{array}$ & M5 & $106^{\circ} 09^{\prime} 50,0^{\prime \prime}$ & $20^{\circ} 11^{\prime} 10,0^{\prime \prime}$ & $\begin{array}{l}\text { Điểm cách ngã ba sông } \\
\text { Quần Liêu khoảng } 500 \mathrm{~m} \\
\text { về phía hạ lưu }\end{array}$ \\
\hline 6 & $\begin{array}{l}\text { Thị trấn } \\
\text { Rạng } \\
\text { Đông }\end{array}$ & & M6 & $106^{\circ} 06^{\prime} 05,0^{\prime \prime}$ & $19^{\circ} 59^{\prime} 08,9^{\prime \prime}$ & $\begin{array}{l}\text { Hạ lưu sông, trước khi đổ } \\
\text { ra biển qua cửa Đáy }\end{array}$ \\
\hline
\end{tabular}




\subsubsection{Phương pháp xử lý thống kê}

Dữ liệu quan trắc được xử lý thống kê bằng phần mềm thống kê chuyên dụng SPSS và R.

\subsubsection{Phương pháp tính chỉ số chất lượng nước (WQI)}

Để tính toán chỉ số WQI nhóm tác giả sử dụng phương pháp của Bộ Tài nguyên và Môi trường đưa ra theo Quyết định số 1460/QĐ-TCMT ngày 12/11/2019 của Tổng cục trưởng Tổng cục Môi trường về việc ban hành Hướng dẫn kỹ thuật tính toán và công bố chỉ số chất lượng nước Việt Nam (VN WQI). Bốn nhóm thông số được sử dụng để tính toán WQI trong nghiên cứu này gồm: Nhóm I: thông số pH; Nhóm III (nhóm thông số kim loại nặng): $\mathrm{Cr}^{6+}$; Nhóm IV (nhóm thông số hữu cơ và dinh dưỡng): $\mathrm{BOD}_{5}, \mathrm{COD}, \mathrm{NH}_{4}{ }^{+}, \mathrm{NO}_{3}{ }^{-}, \mathrm{PO}_{4}{ }^{3-}$; $\mathrm{Nhóm}^{2}$ V (nhóm thông số vi sinh): Coliform.

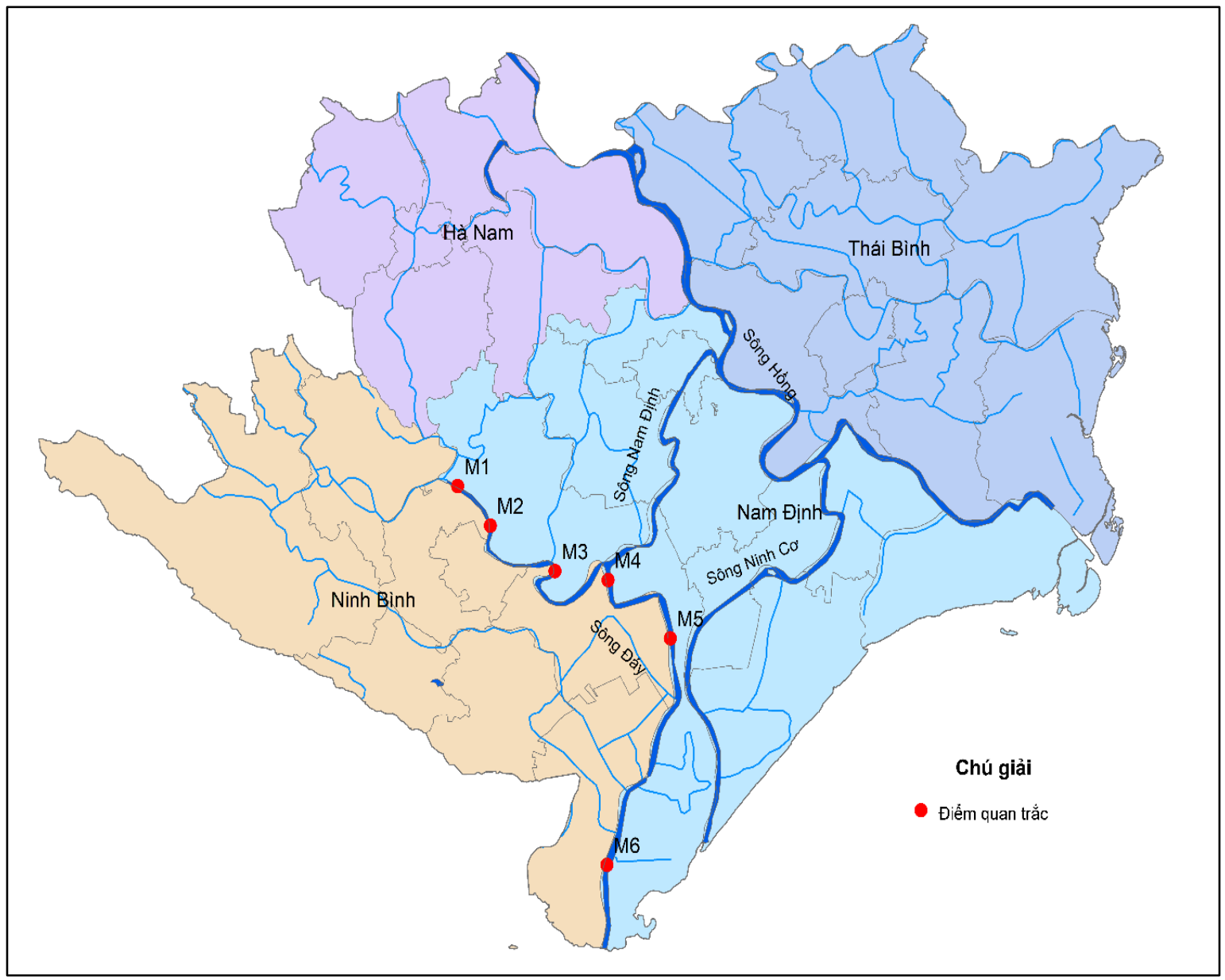

Hình 1. Sơ đồ vị trí các điểm quan trắc.

\section{Kết quả nghiên cứu}

\section{1. Đánh giá diễn biến chất lương nước theo các chỉ tiêu riêng lẻ}

\subsubsection{Diễn biến thông số $\mathrm{pH}$}

Kết quả quan trắc cho thấy $\mathrm{pH}$ dao động trong khoảng từ 6,4 đến 7,18 với giá trị trung bình là 6,91 (Bảng 2), trong đó 75,74\% giá trị pH trong khoảng 6,5-7 (Hình 2). Kết quả cho thấy, thông số $\mathrm{pH}$ có đảm bảo yêu cầu chất lượng nước phục vụ thủy lợi và nuôi trồng thủy sản QCVN 08-MT:2015/BTNMT cột B1. 
Bảng 2. Các giá trị thống kê cơ bản của các thông số.

\begin{tabular}{cccccccc}
\hline TT & Thông số & Trung bình & Trung vị & Độ lệch chuẩn & Min & Max & Sai số chuẩn \\
\hline 1 & $\mathrm{pH}$ & 6,91 & 6,90 & 0,14 & 6,40 & 7,18 & 0,01 \\
2 & $\mathrm{DO}$ & 5,58 & 5,50 & 0,40 & 4,60 & 6,80 & 0,03 \\
3 & $\mathrm{COD}$ & 24,67 & 24,00 & 3,49 & 17,00 & 35,20 & 0,26 \\
4 & $\mathrm{BOD}_{5}$ & 11,76 & 12,00 & 2,42 & 6,00 & 18,00 & 0,19 \\
5 & $\mathrm{TSS}$ & 43,38 & 41,00 & 17,36 & 20,00 & 160,00 & 1,29 \\
6 & $\mathrm{Amoni}$ & 0,17 & 0,15 & 0,08 & 0,02 & 0,38 & 0,01 \\
7 & $\mathrm{NO}_{3}^{-}$ & 0,96 & 0,80 & 0,49 & 0,13 & 2,70 & 0,04 \\
8 & $\mathrm{NO}_{2}^{-}$ & 0,03 & 0,03 & 0,01 & 0,01 & 0,07 & 0,00 \\
9 & $\mathrm{PO}_{4}{ }^{-}$ & 0,15 & 0,12 & 0,09 & 0,01 & 0,40 & 0,01 \\
10 & $\mathrm{Coliform}_{1-}$ & 17,05 & 17,00 & 7,52 & 1,00 & 33,00 & 0,56 \\
11 & $\mathrm{Cr}^{6+}$ & 0,01 & 0,00 & 0,01 & 0,00 & 0,043 & 0,00 \\
\hline
\end{tabular}

\subsubsection{Diễn biến thông số DO}

Trong giai đoạn 2011-2019 nồng độ trung bình của DO trong nước sông là 5,58 mg/l, biến động xung quanh giá trị từ 4,6 mg/l đến $6,8 \mathrm{mg} / \mathrm{l}$ (Bảng 2). Nồng độ $\mathrm{DO}$ tập trung ở các giá trị từ $5-6 \mathrm{mg} / 1$ chiếm $80 \%$ (Hình 2 ). Tất cả các giá trị $\mathrm{DO}$ quan trắc được đều đạt yêu cầu theo QCVN 08-MT:2015/BTNMT cột B1.

\subsubsection{Diễn biến nồng độ COD}

Nồng độ COD giao động từ $17(\mathrm{mg} / \mathrm{l})$ đến 35,2 (mg/l), với giá trị trung bình 24,67 mg/1 (Bảng 2). Nồng độ COD trong giai đoạn 2011-2019 có 93,33\% giá trị nằm dưới QCVN 08 MT:2015/BTNMT cột B1 (Hình 2). Diễn biến nồng độ COD từ 2011-2019 cho thấy, nồng độ $\mathrm{COD}$ đang có xu thế giảm tại tất cả các điểm quan trắc từ M1 đến M6 (Hình 3). Giá trị trung bình nồng độ COD của tất cả các điểm quan trắc năm 2011 là 30,3 đến năm 2019 giảm còn 21,8 . Điều đó cho thấy nồng độ COD trong nước sông Đáy đang có dấu hiệu tốt lên và đều đạt yêu cầu của QCVN 08-MT:2015/BTNMT cột B1.
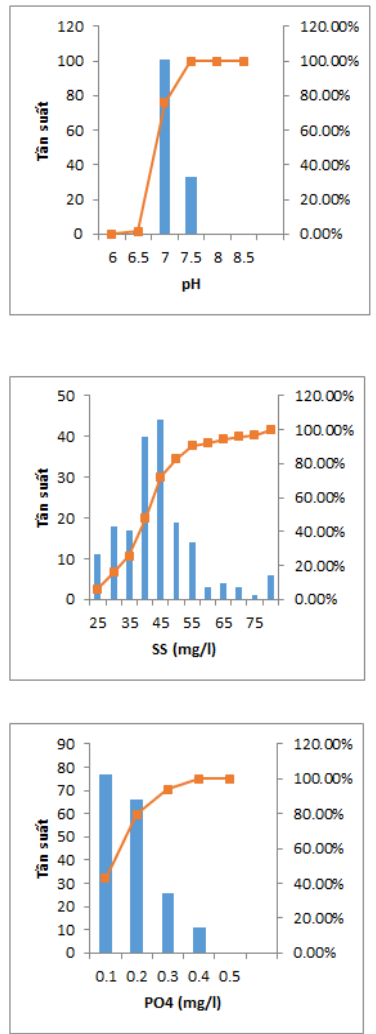
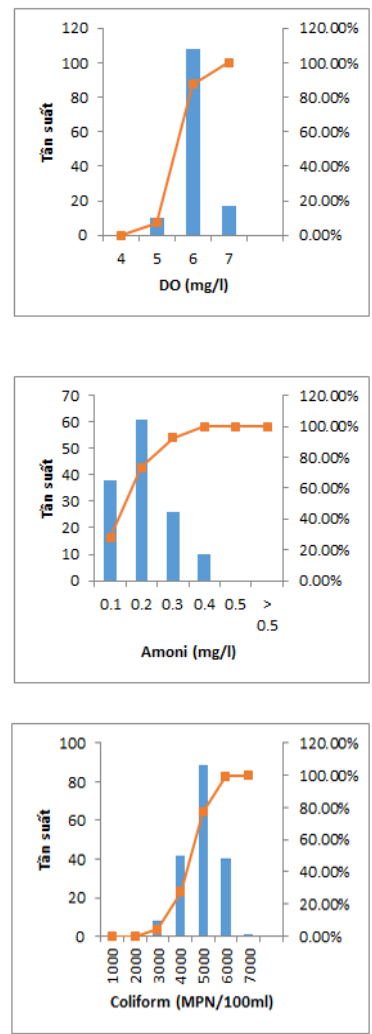
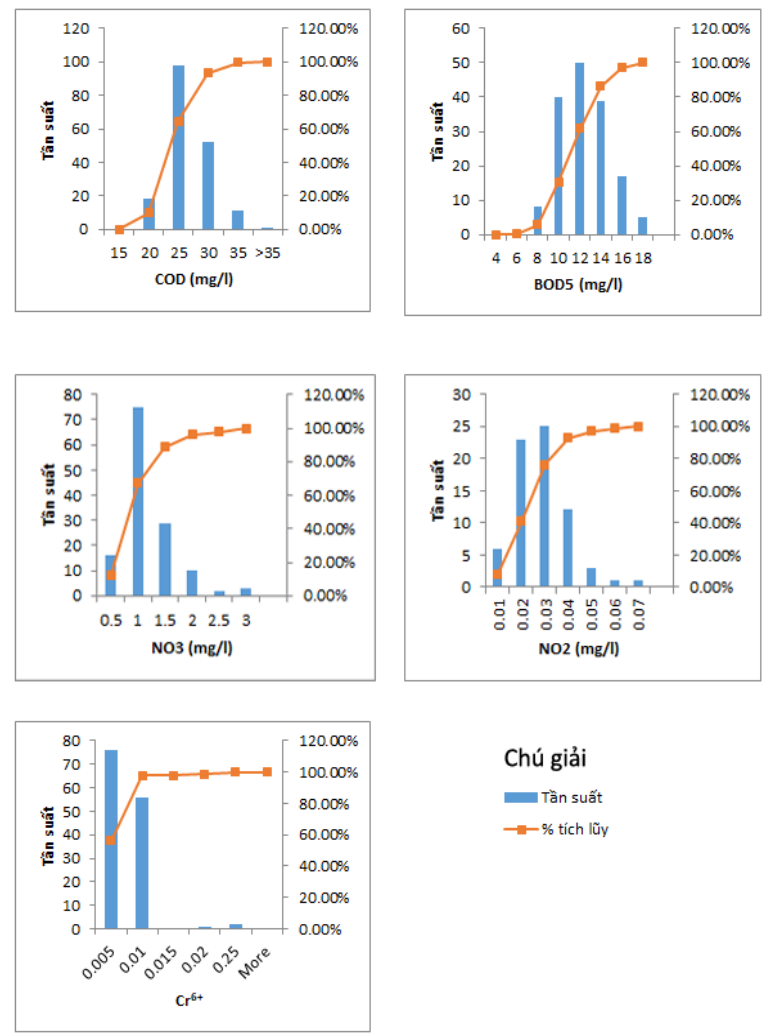

Chú giải

Tần suất

Hình 2. Phân bố nồng độ các chất ô nhiễm giai đoạn 2011-2019. 


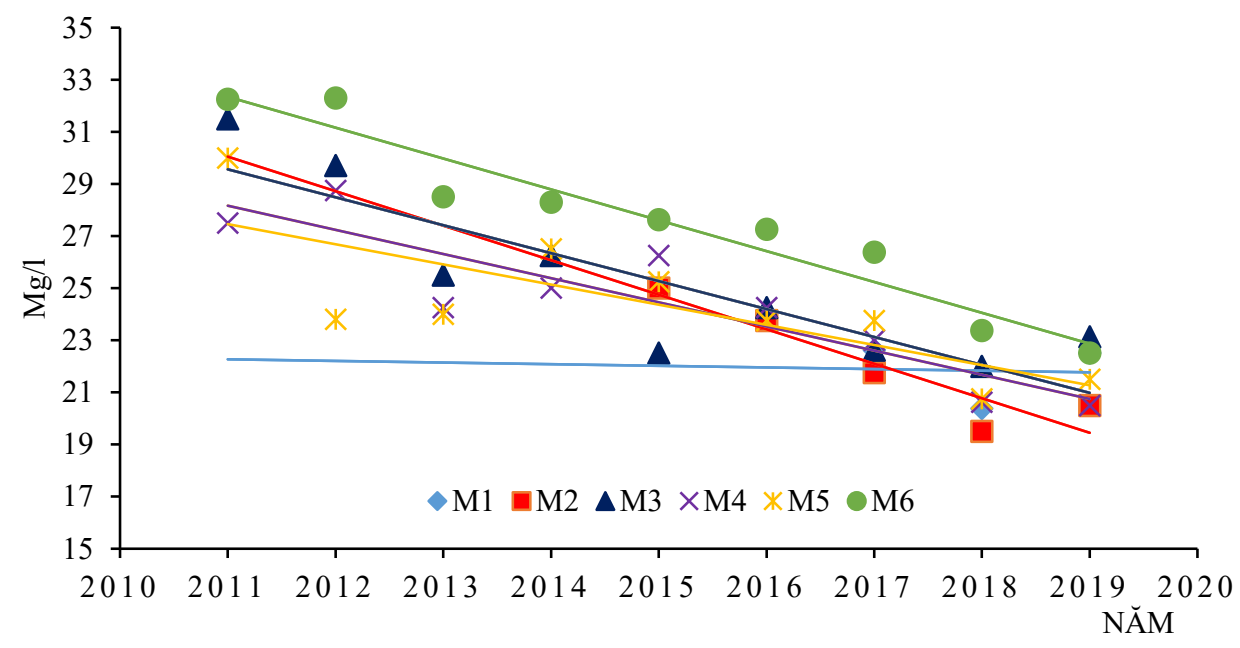

Hình 3. Diễn biến nồng độ COD giai đoạn 2011-2019.

\subsubsection{Diễn biến nồng độ $\mathrm{BOD}_{5}$}

Giá trị $\mathrm{BOD}_{5}$ trong nước mặt sông Đáy giai đoạn 2011-2019 dao động từ $6 \mathrm{mg} / \mathrm{l}$ đến 18 $\mathrm{mg} / \mathrm{l}$, giá trị trung bình năm đạt $11,76 \mathrm{mg} / 1$ nằm dưới ngưỡng $15 \mathrm{mg} / 1$ theo QCVN 08 MT:2015/BTNMT cột $\mathrm{B} 1$. Trong đó $91,30 \%$ các giá trị quan trắc nằm dưới mức Quy chuẩn (Hình 2). Hình 4 cho thấy nồng độ $\mathrm{BOD}_{5}$ đều có xu hướng giảm dần từ năm 2011 đến 2019 với giá trị trung bình năm 2011 từ 15,15mg/l xuống 9,83mg/l năm 2019.

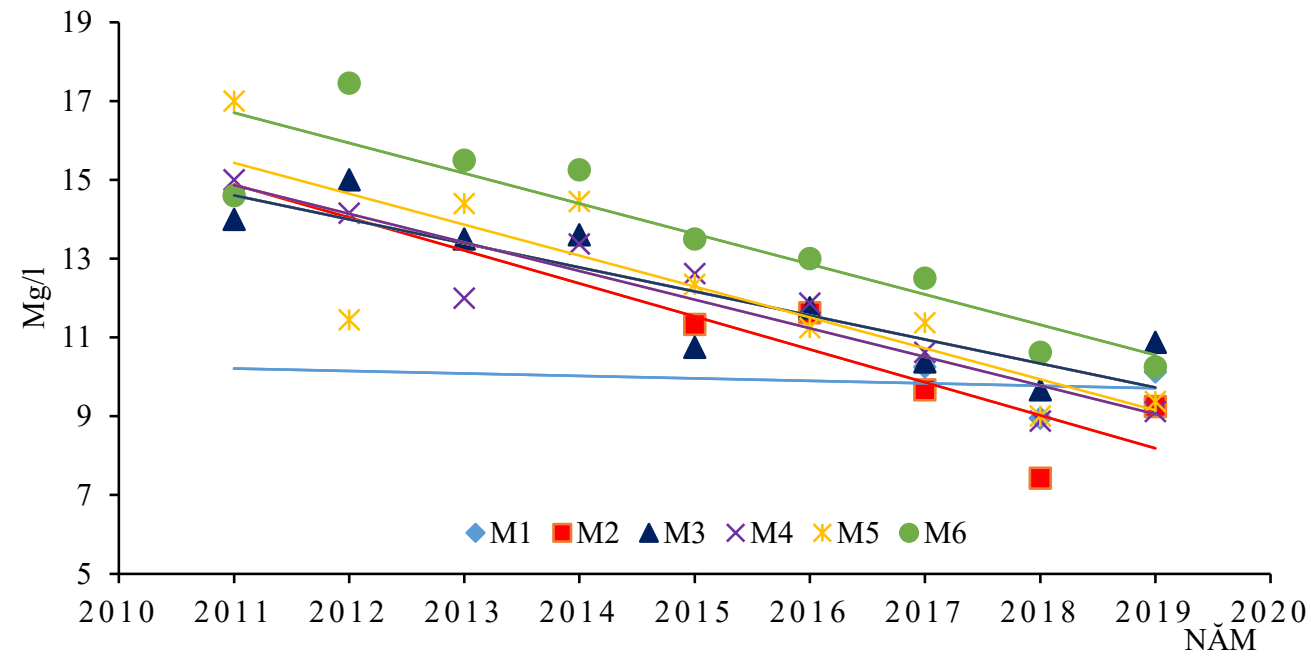

Hình 4. Diễn biến nồng độ $\mathrm{BOD}_{5}$ giai đoạn 2011-2019.

\subsubsection{Diễn biến nồng độ TSS}

Nồng độ TSS giai đoạn 2011-2019 dao động từ 20 đến $160 \mathrm{mg} / 1$ với giá trị trung bình đạt $43,38 \mathrm{mg} / \mathrm{l}$. trong đó có $82,78 \%$ các giá trị quan trắc nằm dưới QCVN 08-MT:2015/BTNMT cột $\mathrm{B} 1(50 \mathrm{mg} / \mathrm{l})$ (Hình 2). Diễn biến nồng độ TSS quan trắc cho thấy xu thế nồng độ TSS trong nước sông Đáy không biến động, ổn định trong khoảng từ 35 đến 50 mg/l (Hình 5).

\subsubsection{Diễn biến nồng độ Amoni, nitrat, nitrit}

Thông số Amoni: Nồng độ Amoni từ năm 2011-2019 dao động từ $0,02 \mathrm{mg} / \mathrm{l}$ đến $0,38 \mathrm{mg} / 1$ với giá trị trung bình $0,17 \mathrm{mg} / \mathrm{l}$ (Bảng 2). Trong đó $100 \%$ các giá trị quan trắc nằm dưới $\mathrm{QCVN}$ 08-MT:2015/BTNMT cột B1 (0,9 mg/1) (Hình 2). Xu thế diễn biến nồng độ Amoni giai đoạn 2011-2019 có dấu hiệu gia tăng (Hình 6) với nồng độ trung bình tăng từ năm $2011(0,131 \mathrm{mg} / \mathrm{l})$ đến năm $2019(0,251 \mathrm{mg} / 1)$. Tuy nhiên mức tăng này vẫn nằm trong giới hạn $\mathrm{QCVN} 08$ MT:2015/BTNMT cột B1. 


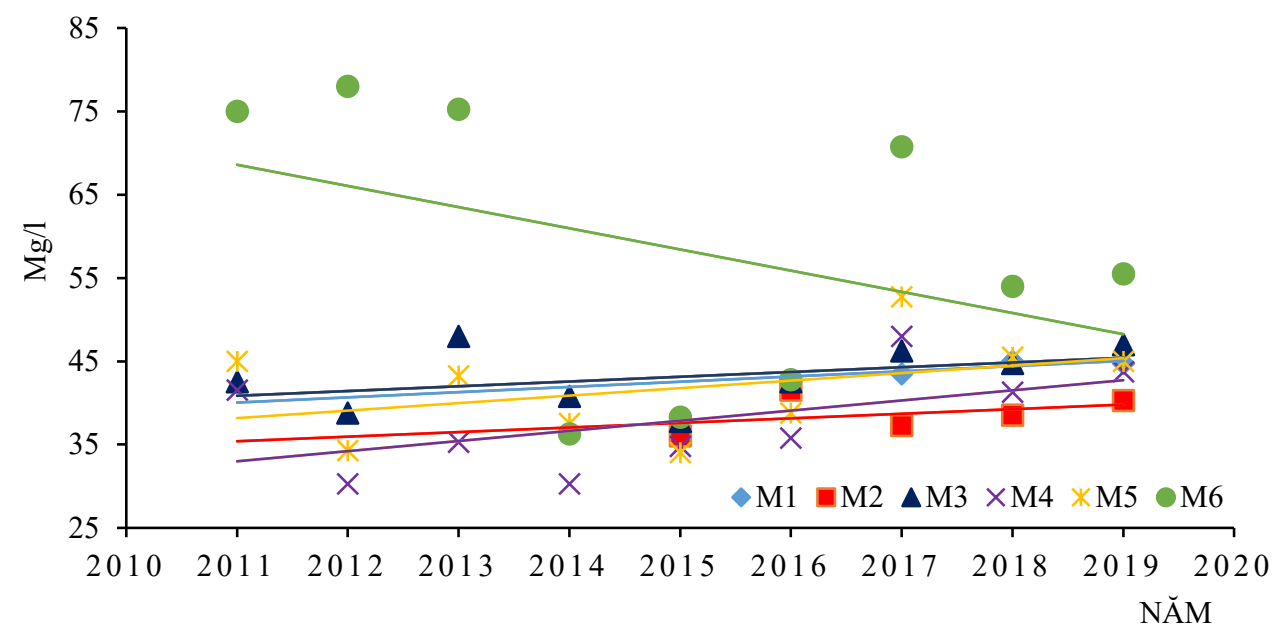

Hình 5. Diễn biến nồng độ TSS giai đoạn 2011-2019.

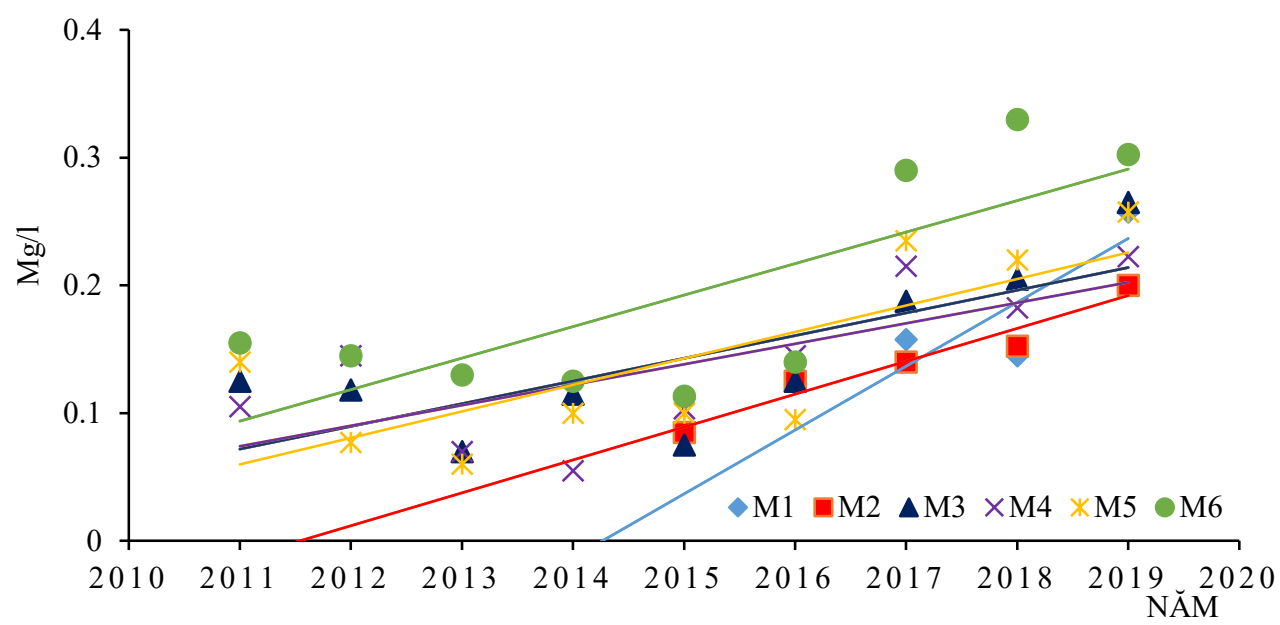

Hình 6. Diễn biến nồng độ Amoni giai đoạn 2011-2019.

Thông số Nitrat: Nồng độ Nitrat trong nước sông Đáy giai đoạn 2011-2019 có xu hướng giảm nhẹ từ năm 2011 (1,02 mg/l) đến năm 2019 (0,81 mg/l) (Hình 7). Với nồng độ trung bình 0,96 $\mathrm{mg} / \mathrm{l}$, giá trị thấp nhất 0,13 giá trị cao nhất $2,7 \mathrm{mg} / 1$. So với QCVN 08-MT:2015/BTNMT cột B1 với thông số Nitrat $(10 \mathrm{mg} / \mathrm{l}), 100 \%$ các giá trị quan trắc đều nằm dưới Quy chuẩn.

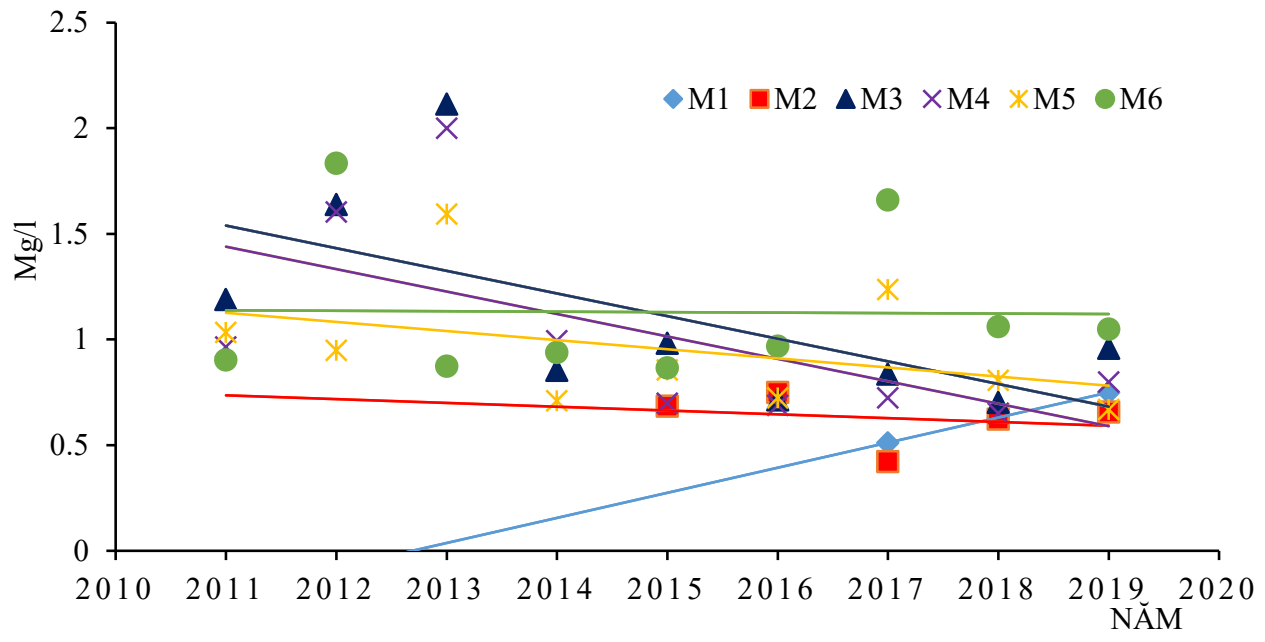

Hình 7. Diễn biến nồng độ Nitrat giai đoạn 2011-2019. 


\subsubsection{Diễn biến nồng độ Phốt phát}

Nồng độ $\mathrm{PO}_{4}{ }^{3-}$ dao động khá lớn từ $0,01 \mathrm{mg} / 1$ đến $0,4 \mathrm{mg} / 1$ với giá trị trung bình giai đoạn 2011-2019 là $0,15 \mathrm{mg} / 1$ (Bảng 2). Có 93.89\% số mẫu quan trắc được nằm dưới QCVN 08-MT:2015/BTNMT cột B1 (0.3 mg/l) (Hình 2). Nồng độ Nồng độ $\mathrm{PO}_{4}{ }^{3-}$ ổn định từ 20122016 và có xu thế tăng nhẹ từ 2017-2019 (Hình 8). Tuy nhiên mức tăng không đáng kể và vẫn nằm dưới QCVN 08-MT:2015/BTNMT cột $\mathrm{B} 1$.

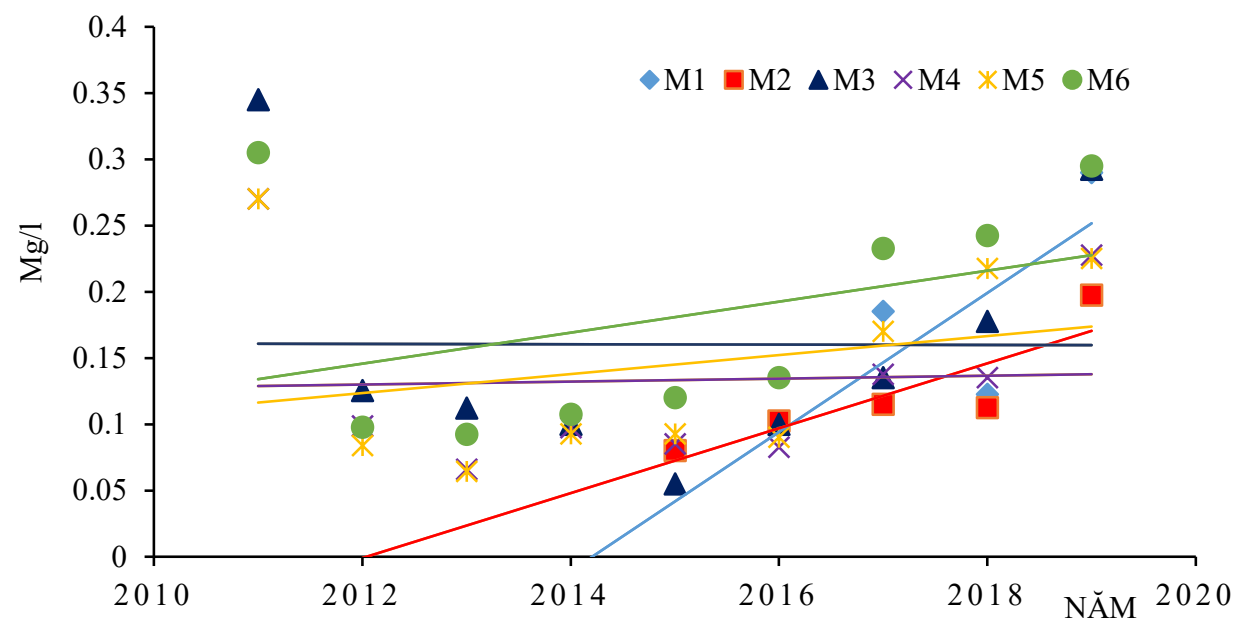

Hình 8. Diễn biến nồng độ Phốt phát giai đoạn 2011-2019.

\subsubsection{Diễn biến nồng độ Coliform}

Nồng độ Coliform khu vực nghiên cứu có xu thế giảm khá rõ rệt từ mức trung bình năm 2011 là 5325 MPN/100ml xuống 4254 MPN/100ml năm 2019 (Hình 9). Tất cả các giá trị quan trắc từ 2011-2019 đều nằm dưới Quy chuẩn QCVN 08-MT:2015/BTNMT cột B1 (7500 $\mathrm{MNP} / 100 \mathrm{ml})$. Trong đó 77,22\% các giá trị quan trắc nằm dưới $5000 \mathrm{MPN} / 100 \mathrm{ml}$ (Hình 2).

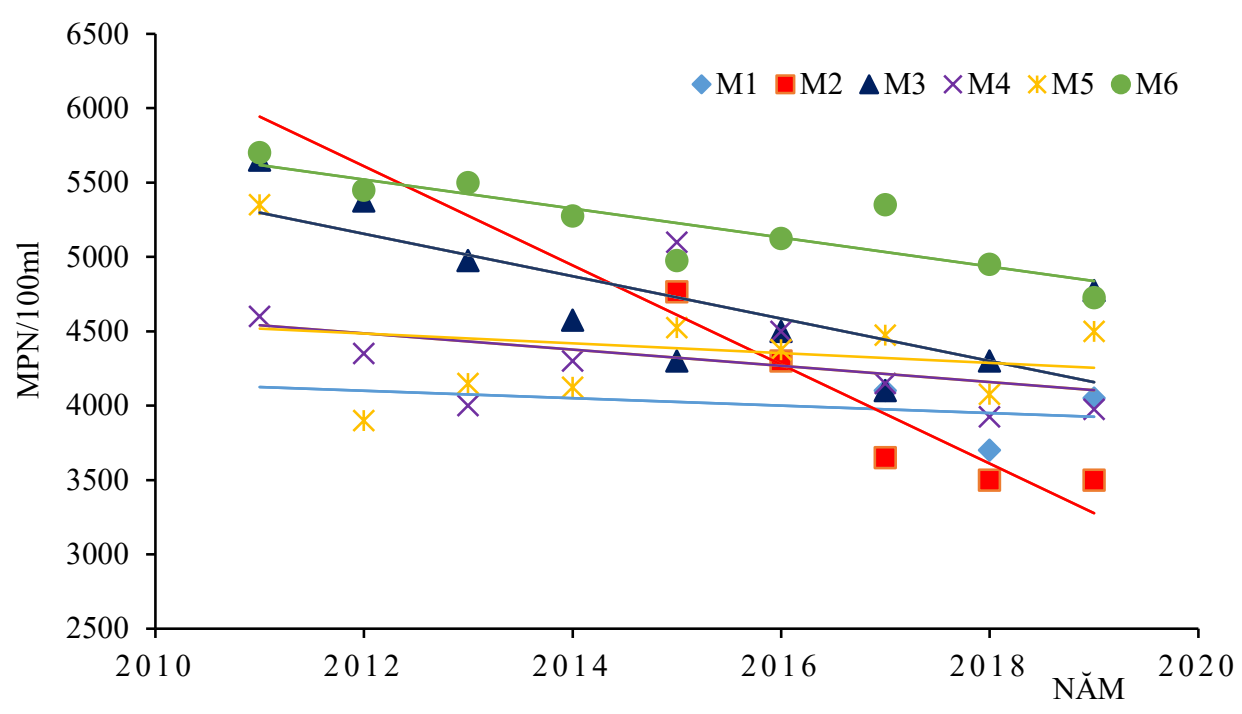

Hình 9. Diễn biến Coliform giai đoạn 2011-2019.

\subsubsection{Diễn biến nồng độ $\mathrm{Cr}^{6+}$}

Nồng độ $\mathrm{Cr}^{6+}$ khu vực nghiên cứu dao động từ $0 \mathrm{mg} / \mathrm{l}$ đến $0,043 \mathrm{mg} / 1$, trong đó 97,78\% số mẫu nằm dưới $0,01 \mathrm{mg} / \mathrm{l}$. Có $98,52 \%$ số mẫu năm dưới Quy chuẩn $\mathrm{QCVN} 08$ MT:2015/BTNMT cột B1 (0.04 mg/l). Nồng độ $\mathrm{Cr}^{6+}$ trong từ năm 2011-2019 xu thế ổn định dưới mức 0,01 mg/l (Hình 10). 


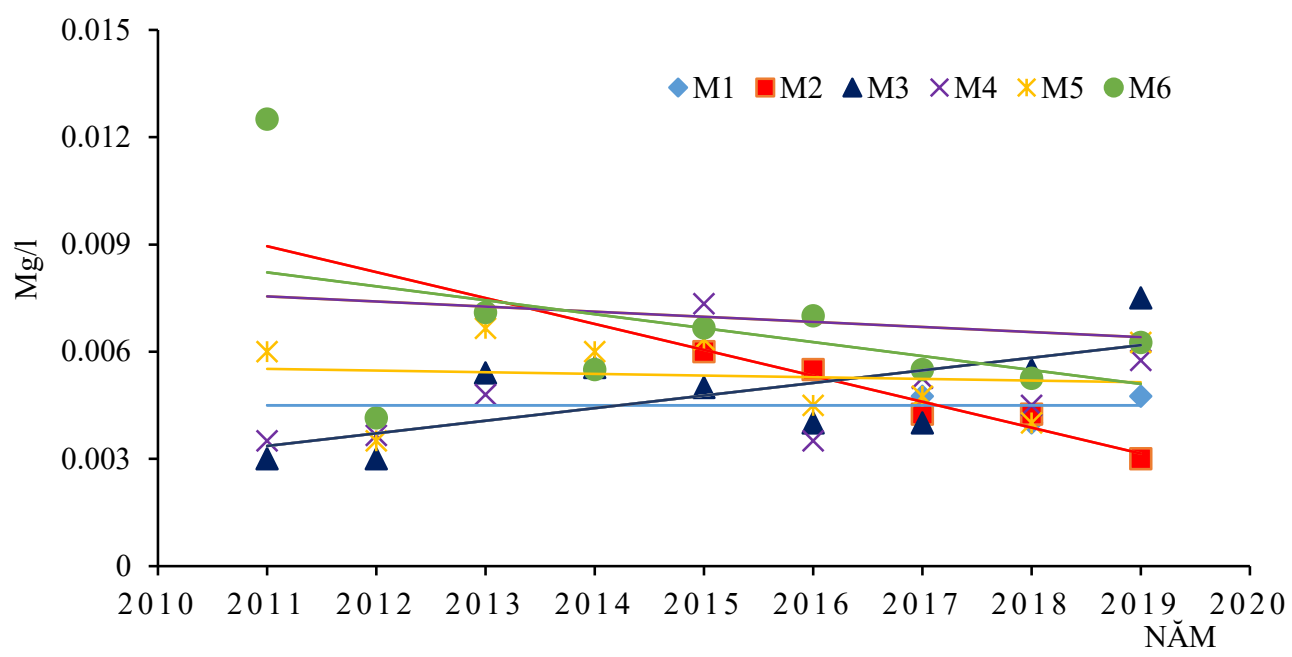

Hình 10. Diễn biến $\mathrm{Cr}^{6+}$ giai đoạn 2011-2019.

\section{2. Đánh giá xu thế diễn biến chất luợng nuớc qua chi số WQI}

Kết quả tính chỉ số chất lượng nước WQI tại các điểm quan trắc trên sông Đáy cho thấy có $84 \%$ các điểm quan trắc có chất lượng nước tốt, $16 \%$ số điểm có chất lượng trung bình, không có điểm nào chất lượng nước kém và ô nhiễm (Bảng 3 ). Diễn biến chất lượng nước tại các điểm từ $\mathrm{M} 1$ đến $\mathrm{M} 5$ có xu thế tăng từ năm 2011 đến năm 2019 và ổn định ở mức tốt. Điểm M6 chất lượng nước tốt lên vào các năm 2012-2016 tuy nhiên giảm đi từ năm 20172019 xuống mức trung bình (Hình 11).

Bảng 3. Chỉ số chất lượng nước sông Đáy giai đoạn 2011-2019.

\begin{tabular}{|c|c|c|c|c|c|c|c|c|c|}
\hline \multirow{2}{*}{$\begin{array}{l}\text { Vị trí } \\
\text { quan } \\
\text { trắc }\end{array}$} & \multicolumn{9}{|c|}{ Giá trị WQI trung bình năm sông Đáy } \\
\hline & 2011 & 2012 & 2013 & 2014 & 2015 & 2016 & 2017 & 2018 & 2019 \\
\hline M1 & 71 & 77 & 78 & 80 & 80 & 82 & 85 & 87 & 79 \\
\hline M2 & & & & & 82 & 83 & 87 & 88 & 88 \\
\hline M3 & 69 & 78 & 80 & 81 & 84 & 82 & 85 & 84 & 76 \\
\hline M4 & 74 & 81 & 84 & 83 & 80 & 83 & 84 & 86 & 82 \\
\hline M5 & 71 & 85 & 83 & 82 & 82 & 83 & 83 & 82 & 80 \\
\hline M6 & 65 & 76 & 77 & 78 & 79 & 80 & 74 & 73 & 73 \\
\hline
\end{tabular}

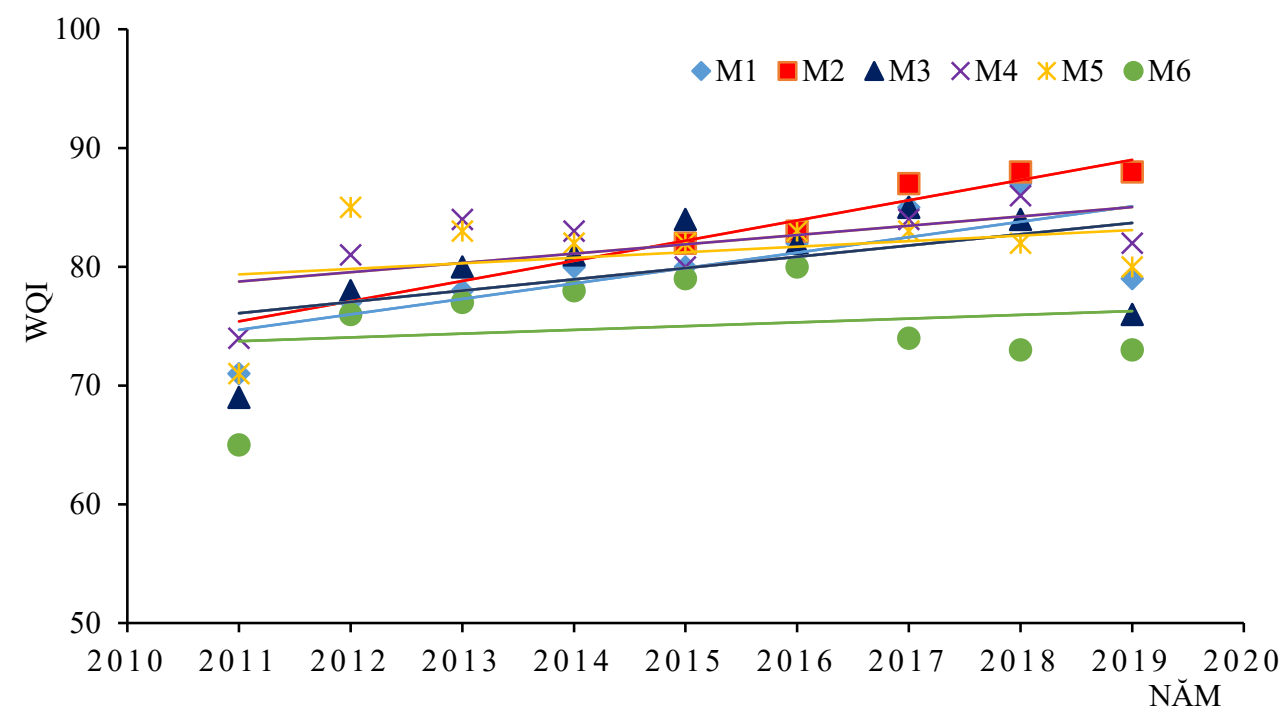

Hình 11. Diễn biến chất lượng nước sông Đáy giai đoạn 2011-2019. 


\section{Kết luận}

Nghiên cứu chỉ ra rằng các thông số $\mathrm{COD}, \mathrm{BOD}_{5}$, Nitrat, Coliform có xu thế giảm từ 2011-2019, thông số $\mathrm{NH}_{4}^{+}$có xu thế tăng nhẹ, các thông số TSS, $\mathrm{PO}_{4}^{3-}, \mathrm{Cr}^{6+}$ có xu thế ổn định.

Chất lượng nước sông Đáy đoạn chảy qua tỉnh Nam Định có chất lượng tốt. Diễn biến chất lượng nước ngày càng được cải thiện từ 2011-2019. Các giá trị trung bình quan trắc từ 2011-2019 đều nằm dưới QCVN 08-MT:2015/BTNMT cột B1. Chỉ số WQI cho thấy $84 \%$ số điểm quan trắc có chất lượng nước tốt, $16 \%$ có chất lượng nước trung bình.

Với chất lượng nước sông tốt, tỉnh Nam Định có thể sử dụng nước sông phục vụ cho các mục tiêu phát triển kinh tế xã hội của tỉnh và khu vực.

Nghiên cứu còn một số hạn chế như số liệu về thông số thuốc bảo vệ thực vật chưa được đưa vào tính chỉ số WQI. Nguyên nhân chính xác dẫn tới sự thay đổi chất lượng nước cần có nghiên cứu sâu hơn.

Lời cảm ơn: Tác giả xin trân trọng cảm ơn Trung tâm Quan trắc Tài nguyên và Môi trường tỉnh Nam Định đã cung cấp số liệu cho nghiên cứu này.

Đóng góp của tác giả: Xây dựng ý tưởng nghiên cứu: Đ.H.T., L.T.D.; Lựa chọn phương pháp nghiên cứu: Đ.H.T., L.T.D.; Thu thập, phân tích, tính toán xử lý số liệu: Đ.H.T., L.T.D.; Viết bản thảo bài báo: Đ.H.T., L.T.D.; Chỉnh sửa bài báo: Đ.H.T.

Lò̀i cam đoan: Tác giả cam đoan bài báo này là công trình nghiên cứu tác giả, chưa được công bố ở đâu, không sao chép từ những nghiên cứu trước đây; không có sự tranh chấp lợi ích.

\section{Tài liệu tham khảo}

1. Effendi, H.R.; Yusli, W. Water Quality Status of Ciambulawung River, Banten Province, Based on Pollution Index and NSF-WQI. Procedia Environ. Sci. 2015, 24, $228-237$.

2. Luo, Z.L.; Quanxi, S.; Huan, L. Comparative evaluation of river water quality and ecological changes at upstream and downstream sites of dams/sluices in different regulation scenarios. J. Hydrol. 2021, 597, 126290.

3. Akoto, O.; Adopler, A.; Tepkor, H.E.; Opoku, F. A comprehensive evaluation of surface water quality and potential health risk assessments of Sisa river, Kumasi. Groundwater Sustainable Dev. 2021, 15, 100654.

4. Chai, N.; Yi, X.; Xiao, J.; Liu, T.; Liu, Y.; Deng, L.; Jin, Z. Spatiotemporal variations, sources, water quality and health risk assessment of trace elements in the Fen River. Sci. Total Environ. 2021, 757, 143882.

5. Zeleňáková, M.; Kubiak-Wojcicka, K.; Weiss, R.; Weiss, E.; Elhamid, H.F.A. Environmental risk assessment focused on water quality in the Laborec River watershed. Ecohydrol. Hydrobiol. 2021. https://doi.org/10.1016/j.ecohyd.2021.06.002.

6. Carere, M.; Antoccia, A.; Buschini, A.; Frenzilli, G.; Marcon, F.; Andreoli, C.; Gorbi, G.; Suppa, A.; Montalbano, S.; Prota, V.; De Battistis, F.; Guidi, P.; Bernardeschi, M.; Palumbo, M.; Scarcelli, V.; Colasanti, M.; D'Ezio, V.; Persichini, T.; Scalici, M.; Sgura, A.; Spani, F.; Udroiu, I.; Valenzuela, M.; Lacchetti, I.; Di Domenico, K.; Cristiano, W.; Marra, V.; Ingelido, A.M.; Iacovella, N.; De Felip, E.; Massei, R.; Mancini, L. An integrated approach for chemical water quality assessment of an urban river stretch through Effect-Based Methods and emerging pollutants analysis with a focus on genotoxicity. J. Environ. Manage. 2021, 300, 113549. 
7. O’Donoghue, C.; Meng, Y.; Ryan, M.; Kilgarriff, P.; Zhang, C.; Bragina, L.; Daly, $\mathrm{K}$. Trends and influential factors of high ecological status mobility in Irish Rivers. Sci. Total Environ. 2021, 151570.

8. Kumar, A.; Taxak, A. K.; Mishra, S.; Pandey, R. Long term trend analysis and suitability of water quality of River Ganga at Himalayan hills of Uttarakhand, India. Environ. Technol. Innovation 2021, 22, 101405.

9. Geng, M.; Wang, K.; Yang, N.; Li, F.; Zou, Y.; Chen, X.; Deng, Z.; Xie, Y. Evaluation and variation trends analysis of water quality in response to water regime changes in a typical river-connected lake (Dongting Lake), China. Environ. Pollut. 2021, 268, 115761.

10. Trang, H.T.; Luyện, N.Đ.; Huyền, Đ.D. Nghiên cứu đánh giá chất lượng nước sông Gianh. Tạp chí Khoa học, Truò̀ng Đại học Su phạm, Đại học Huế 2019, 03(51), 93100.

11. Sultana, M.S.; Ashraf, D. A reflectance-based water quality index and its application to examine degradation of river water quality in a rapidly urbanising megacity. Environ. Adv. 2021, 5, 100097.

12. Jain, N.; Rudrani, Y.; Tarul, S.R. Comparative study of physico-chemical parameters and water quality index of river. Materials Today: Proceedings 2021. https://doi.org/10.1016/j.matpr.2021.09.508.

13. Jyothi, S.N.; Gevargis, M.T.; Rohith Raj, R.V.; Akhil, M.; Akhil, T.; Manaswini, M.; Gutlapalli, N.C. Assessment of water quality Index and study of the impact of pollution on the rivers of Kerala. Materials Today: Proceedings 2021, 43, 34473451.

14. Tabrez, S.; Torki, A.Z.; Mehjbeen, J. Water quality index, Labeo rohita, and Eichhornia crassipes: Suitable bio-indicators of river water pollution. Saudi J. Biol. Sci. 2021. https://doi.org/10.1016/j.sjbs.2021.10.052.

15. Howladar, M. F.; Chakma, E.; Jahan, K.N.; Islam, S.; Numanbakth, M.A.A.; Ahmed, Z.; Chowdhury, T.R.; Akter, S. The water quality and pollution sources assessment of Surma river, Bangladesh using, hydrochemical, multivariate statistical and water quality index methods. Groundwater Sustainable Dev. 2021, 12, 100523.

16. Sudhakaran, S.; Mahadevan, H.; Arun, V.; Krishnakumar, A.P.; Krishnan, K.A. A multivariate statistical approach in assessing the quality of potable and irrigation water environs of the Netravati River basin (India). Groundwater Sustainable Dev. 2020, 11, 100462.

17. Jessica, U.C.; Estilita, R.R.; Miren, M.S.; Maider, V.; Iñaki, A. Multivariate statistical analyses for water and sediment quality index development: A study of susceptibility in an urban river. Sci. Total Environ. 2020, 711, 135026.

18. Njuguna, S.M.; Onyango, J.A.; Githaiga, K.B.; Gituru, R.W.; Yan, X. Application of multivariate statistical analysis and water quality index in health risk assessment by domestic use of river water. Case study of Tana River in Kenya. Process Saf. Environ. Prot. 2020, 133, 149-158.

19. Fan, X.; Cui, B.; Zhao, H.; Zhang, Z.; Zhang, H. Assessment of river water quality in Pearl River Delta using multivariate statistical techniques. Procedia Environ. Sci. 2010, 2, 1220-1234.

20. Liu, C.; Pan, C.; Chang, Y.; Luo, M. An integrated autoregressive model for predicting water quality dynamics and its application in Yongding River. Ecol. Indic. 2021, 133, 108354.

21. Qi, J.; Zhang, X.; Yang, Q.; Srinivasan, R.; Arnold, J.G.; Li, J.; Waldholf, S.T.; Cole, J. SWAT ungauged: Water quality modeling in the Upper Mississippi River Basin. J. Hydrol. 2020, 584, 124601. 
22. Krtolica, I.; Cvijanović, D.; Obradović, Đ.; Novković, M.; Milošević, D.; Savić, D.; Vojinović-Miloradov, M.; Radulović, S. Water quality and macrophytes in the Danube River: Artificial neural network modelling. Ecol. Indic. 2021, 121, 107076.

23. Rajaee, T.; Salar, K.; Masoud, R. Artificial intelligence-based single and hybrid models for prediction of water quality in rivers: A review. Chemom. Intell. Lab. Syst. 2020, 200, 103978.

24. Trang, K.T.T. Đánh giá mức độ ô nhiễm và rủi ro sinh thái của một số kim loại nặng trong trầm tích khu vực hạ lưu sông Đáy. Luận văn thạc sỹ, Đại học Quốc gia Hà Nội, Việt Nam, 2018.

25. Lê Thị Trinh, Kiều Thị Thu Trang, Nguyễn Thành Trung, Nguyễn Khánh Linh, Trịnh Thị Thắm. Đánh giá sự tích lũy và rủi ro sinh thái một số kim loại nặng trong trầm tích mặt khu vực hạ lưu sông Đáy. Tạp chí Khoa hoc ĐHQGHN: Các Khoa hoc Trái đất và Môi trường 2018, 34(4), 140-147.

\title{
Assessment of water quality trend of Day River section in Nam Dinh Province from 2011-2019
}

\section{Do Huu Tuan ${ }^{1 *}$, Le Thuy Dieu ${ }^{1}$}

${ }^{1}$ Faculty of Environmental Sciences, VNU University of Science, Vietnam National University, Hanoi; tuandh@vnu.edu.vn; dieuthuy.mt45@gmail.com

\begin{abstract}
River water quality trend is one of the important parts of environmental management in general and water quality management in particular. Water quality assessment results serve as a basis for decisions on environmental management and protection plans. Water quality assessment by individual parameter, water quality index, and water quality trend analysis methods were used in this research to assess the water quality trend of the Day River section in Nam Dinh province from 2011-2019. The trend analysis results showed that $\mathrm{COD}, \mathrm{BOD}_{5}$, Nitrate, and Coliform concentration trend decreased from 2011-2019; $\mathrm{NH}_{4}{ }^{+}$slicely increased; while $\mathrm{TSS}, \mathrm{PO}_{4}{ }^{3-}$, and $\mathrm{Cr}^{6+}$ concentration were stable. The research's results showed that water quality of the Day River section in Nam Dinh province had good quality and improved its quality from 2011-2019. The average monitored parameters concentration from 2011-2019 were under the QCVN 08-MT:2015/BTNMT column B1.
\end{abstract}

Keywords: Water quality; River water quality trend; Day River; WQI. 